\title{
Habituation of two response systems in the lizard, Anolis carolinensis
}

\author{
DAVID J. GUBERNICK \\ University of Virginia, Charlottesville, Virginia 22901 \\ and \\ JOHN W. WRIGHT \\ Washington State University, Pullman, Washington 99163
}

\begin{abstract}
These experiments investigated habituation of two responses in the lizard Anolis carolinensis. In Experiment 1, intertrial intervals (ITI) of 5, 30, and $120 \mathrm{sec}$ had various effects on habituation of dewlap distension and optokinetic response (OKR). Although there were no size differences noted for the OKR, smaller anoles (50-58 mm snout-vent length, SVL) failed to habituate under the 30 - and 120-sec ITI of the dewlap response, while larger anoles $(\geqslant 59-\mathrm{mm}$ SVL) habituated under each ITI tested, with no response level differences between ITIs. Rates of habituation were similar within and across responses. In a second experiment, larger anoles were employed to study recovery and retention of dewlap distension and OKR habituation after 15-min and 24-h intervals. Complete recovery of both responses occurred in $24 \mathrm{~h}$, with substantial recovery of both responses after $15 \mathrm{~min}$. Retention was present for both responses after $15 \mathrm{~min}$ but not after $24 \mathrm{~h}$. A multiple response-system approach is offered as a promising method for research and theories in habituation. Rather than concentrating upon a single response in one or more species, a multiple response-system approach examines similarities and differences in the habituation of various responses within a single species.
\end{abstract}

According to Thompson and Spencer (1966), there is virtually complete agreement in the parametric characteristics of habituation in a wide variety of species and responses, implying that similarities in habituation far outweigh any differences. Thompson and Spencer further suggest that habituation is relatively unaffected by the particular species or response under investigation. Contrary to this view, other investigators have suggested that certain selection pressures may have favored the development of habituatory processes and mechanisms. Habituation of some responses is thought to have evolved because reduced responding to biologically irrelevant stimuli enhanced survival (Lorenz, 1965; Petrinovich, 1973; Thorpe, 1963; Wyers, Peeke, \& Herz, 1973). Thus, similarities and differences between responses and

This article is based on a dissertation submitted by the first author to Fordham University in partial fulfillment of the PhD requirements. A briefer version of Experiment 1 was presented at the 46th meeting of the Eastern Psychological Association, New York City, 1975. Our thanks are extended to Paul E. Gold, Peter H. Klopfer, and two anonymous reviewers for their helpful comments, to John Walsh for his statistical advice, Richard Galente for his invaluable technical assistance, and Nargis Cross for typing the manuscript; a special work of thanks is due to Henry $\mathbf{R}$. Askew, who provided the impetus for this line of research. Requests for reprints should be sent to: David J. Gubernick, Zoology Department, Duke University, Durham, North Carolina 27706. species in the parameters of habituation would be expected depending upon the particular response system and the presumed similarities and differences in past selection. This evolutionary perspective suggests focusing attention on comparative studies of habituation as a means of assessing these possibilities.

Although habituation has been investigated in many species and for many responses (cf. Harris, 1943; Thompson \& Spencer, 1966; Thorpe, 1963), there are few systematic comparative studies either across species (e.g., Clark, 1960; Evans, 1969a, 1969b; Groswald \& Luttges, 1974) or across responses. Rather, habituation studies frequently employ a single response or response system with the presentation of either one stimulus (e.g., Askew, Leibrecht, \& Ratner, 1969; Ewert \& Ingle, 1971) or different stimuli (e.g., Figler, 1972; Leaton, 1974). In contrast, the present study was concerned with the development of a multiple response-system approach derived from an evolutionary perspective. This perspective emphasizes the likelihood of finding similarity and diversity in the parameters of habituation for various response systems, even within the same species.

There is a paucity of research on habituation in reptiles (Goodman \& Weinberger, 1973). The available reptilian data are concerned with habituation 
in turtles (e.g., Crampton \& Schwam, 1962; Hayes, Hertzler, \& Hogberg, 1968; Hayes \& Saiff, 1967; Humphrey, 1933) and snakes (e.g., Burghardt, 1966; Chiszar, Carter, Knight, Simonsen, \& Taylor, 1976; Czaplicki, 1975; Fuenzalida, Ulrich, \& Ichikawa, 1975), with little known about lizards. In the present experiments, the lizard Anolis carolinensis, commonly referred to as the "American chameleon," was chosen for study.

\section{GENERAL METHOD}

\section{Animals}

A. carolinensis are small, mainly arboreal, diurnal lizards found throughout the southeastern United States (Conant, 1975). Although $A$. carolinensis has been well studied in other contexts (cf. Burghardt, 1964; Crews, 1975c; Licht, 1971), to our knowledge there has been only one demonstration of learning in $A$. carolinensis (Powell, 1967).

A. carolinensis were captured in Louisiana and purchased from Charles P. Chase Co., Miami, Florida. Upon arrival, the animals were checked for good physical condition, snout-vent length (SVL) measured, dorsal surfaces numbered in ink, and assigned to a home cage. Groups of 20 animals were caged in screen-covered wooden boxes $(74.9 \times 32.4 \times 44.5 \mathrm{~cm})$ containing branches and artificial leaves for perching and climbing. Water was provided ad lib and was also sprinkled twice daily on leaves and branches. Anoles were fed live Tenebrio molitor mealworms every 3-4 days. Three 38-liter aquaria, filled with water and placed in the colony room, provided additional moisture. Six $25-\mathrm{W}$ light bulbs were suspended $54.6 \mathrm{~cm}$ above the home cages and were kept on a 12-h light-dark cycle initiated at $0800 \mathrm{~h}$. Temperature in the colony room ranged between $25^{\circ}-27^{\circ} \mathrm{C}$ and $27^{\circ}-28^{\circ} \mathrm{C}$ during testing. All animals were kept in the laboratory at least 2 weeks prior to testing. The animals were periodically checked, and unhealthy specimens were replaced.

\section{Response Systems}

As defined here, a response system refers to a functionally integrated behavior pattern that is comprised of one or more components and is shown in a specific context. For example, the aggressive display of male Siamese fighting fish (shown towards another male) consists of several components (e.g., gill cover erection, spreading of fins), but is here considered as one response system. Studying two or more such response systems thus characterizes a multiple response-system approach as developed below.

The absence of behavioral studies directly relevant to our interests in habituation and the lack of knowledge about various response systems of $A$. carolinensis made extensive pilot work necessary. Two responses were finally selected because of their probable importance in the life of $A$. carolinensis. These included dewlap extension and optokinetic response (OKR).

The dewlap response refers to the distension of the "throat fan" located beneath the throat of $A$. carolinensis and many other lizard species (Conant, 1975). In $A$. carolinensis dewlap extension normally occurs as part of the display given during social and courtship behavior, conspecific fighting, and territorial defense (Crews, 1975a, 1975b; B. Greenberg \& Noble, 1944; N. Greenberg, 1977; Noble \& Bradley, 1933), and in many anoline lizards may act as an isolating mechanism for species recognition (Williams \& Rand, 1977). In male assertion displays, head nodding and pushups (body elevation via leg extension) are accompanied by brief extensions of the dewlap, while challenge displays start as assertion displays but include saggital expansion of the body, stalking, lunging, or biting (with the dewlap omitted), and jaw-sparring (Crews, 1975b; N. Greenberg,
1977). Courtship displays also begin with the assertion pattern, with coordinated head nods and pushups changing to shallow rapid nodding after dewlap retraction (N. Greenberg, 1977). The present response consisted of a pushup, dewlap distension, and mouth open or gape typically directed at the test stimulus. Head nods were absent.

The OKR refers to distinct head movements (following) of an anole when surrounded by a field of moving stripes, and was characterized by lateral head turning and a snapping back to midline. An OKR serves to stabilize the image of a moving object on the retina (Polyak, 1957) and is probably involved in visually guided behavior such as capture of prey and locomotion (Tauber \& Atkin, 1968) and has also been correlated with microhabitat illumination in several anoline lizards, including A. carolinensis (Jenssen \& Swenson, 1974).

\section{Apparatus}

The dewlap response apparatus, shown in Figure 1, consisted of a clear container which housed a stimulus bird and which was placed within a transparent cylinder, thereby forming a runway. A perforated cover with a $12.7-\mathrm{cm}$ center hole was placed over the cylinder to prevent escape and permit up and down movement of the white sleeve. A cord tied to the white sleeve was attached via a pulley to a revolving crossbar on a motor. The white sleeve was raised during a trial, exposing a stimulus bird to view, and lowered during the intertrial interval. The bird, a live house sparrow, Passer domesticus, was kept active throughout a trial by a circular support disk, which revolved at $10 \mathrm{rpm}$. $P$. domesticus was employed because it best elicited the dewlap response in comparison to several other birds, rodents, or conspecifics. The dewlap apparatus was mounted on a white board and was placed within an enclosure, $8.9 \mathrm{~cm}$ from the bottom.

The OKR apparatus, shown in Figure 2, consisted of a transparent cylinder $(15.2 \times 30.5 \mathrm{~cm}$ across the top and $26.7 \mathrm{~cm}$ across the bottom) mounted on a $22.2-\mathrm{cm}$ shaft that was attached to a motor. Twelve $1.91-\mathrm{cm}$-wide stripes of nonreflective black tape were placed at $6.35-\mathrm{cm}$ intervals around the outside of the cylinder. A clear container $(13.3 \times 15.2 \mathrm{~cm}$ across) was suspended from rods attached to the top of an enclosure and was centered

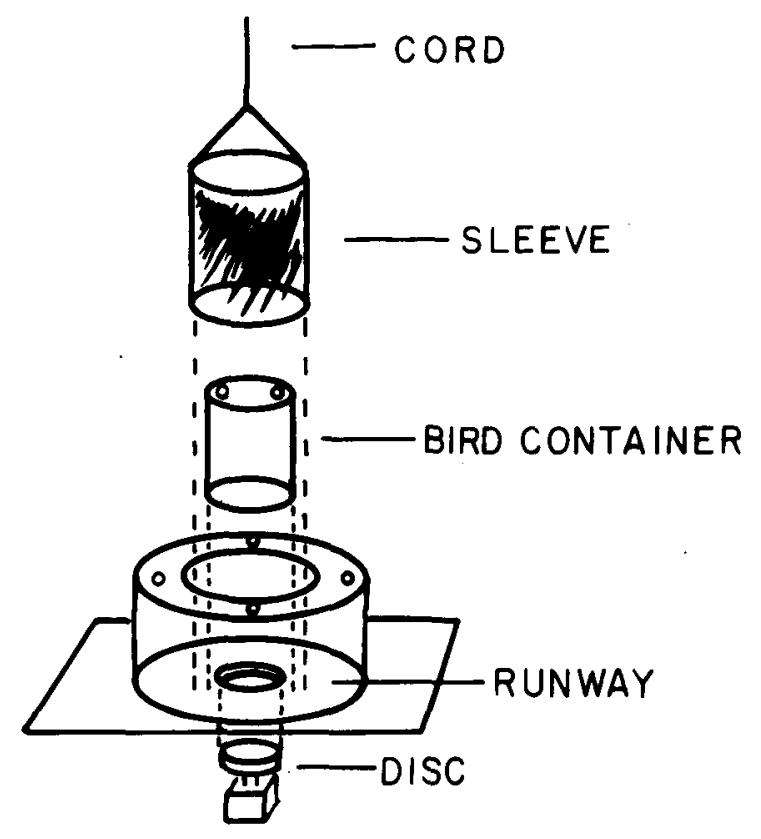

Figure 1. Dewlap response apparatus: Sleeve $(18.4 \mathrm{~cm}$ high $\times$ $12.7 \mathrm{~cm}$ across $)$, bird container $(14 \times 12.1 \mathrm{~cm}$ across $)$, cylinder $(13.3 \times 25.4 \mathrm{~cm}$ across $)$, and runway $(12.7 \times 6.4 \mathrm{~cm}$ across $)$. 


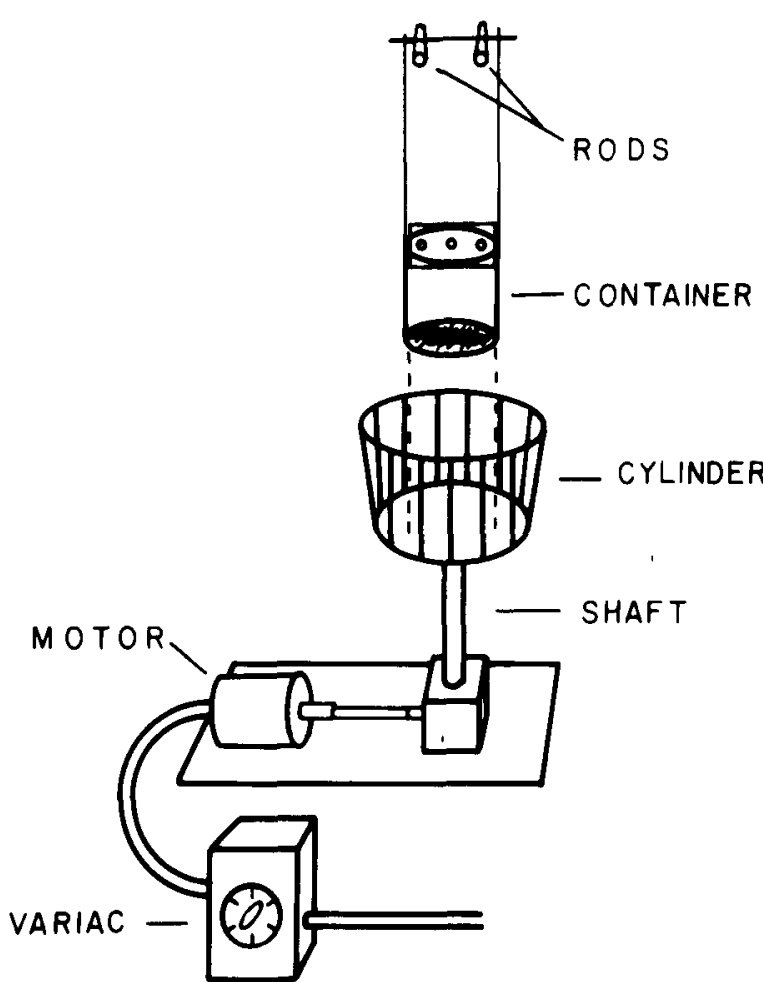

Figure 2. Optokinetic response apparatus, motor, and variac speed control.

within the striped cylinder, $3.8 \mathrm{~cm}$ from the bottom. An animal was placed unrestrained inside the container, and a perforated cover prevented escape. The motor and striped cylinder were placed such that the striped cylinder extended $25.4 \mathrm{~cm}$ into the enclosure. The striped cylinder rotated counterclockwise at $12 \mathrm{rpm}$.

Each apparatus was placed within a wooden enclosure (inner dimensions: $38.1 \times 38.1 \times 53.3 \mathrm{~cm}$ high) painted flat-white and equipped with removable sides, a one-way mirror, $15-\mathrm{W}$ light bulb, and an exhaust fan. The enclosure rested on two stands placed $38.1 \mathrm{~cm}$ apart. The pulley system used for the dewlap apparatus was located on the outside top and side panels of the enclosure. The light from the enclosure and a discrimination light mounted on the recording stand provided the only illumination in the experimental room.

All stimulus presentations and intertrial intervals were programmed with electromechanical equipment which controlled the onset and offset of the motor, while response measures were recorded by hand. A stopwatch was used to determine all duration measures.

\section{Procedure}

At the time of testing, an anole was removed from its home cage, placed in the experimental apparatus for $5 \mathrm{~min}$ adaptation, tested, removed, and returned to its home cage. The response measures recorded were the duration of dewlap extension, mouthopen, and frequency of head following in the direction of rotation of the moving stripes (OKR). Since the frequency of dewlap extension was usually one or two per trial, and rarely exceeded three, frequency was not analyzed. Mean Pearson $r$ interrater reliabilities between the observations of each of three inexperienced judges with those of the first author were +.97 and +.96 for the dewlap response, and OKR, respectively. Observations were taken between 0900 and $1900 \mathrm{~h}$ (EST and DST) during the nonbreeding season of September to March.

The effects of intertrial interval and the time course of spontaneous recovery were studied in Experiments 1 and 2, respectively.
These two parametric characteristics of habituation (Thompson \& Spencer, 1966) were selected because response habituation has not been previously demonstrated in $A$. carolinensis, and this basic descriptive information was considered necessary for future behavioral research.

\section{EXPERIMENT 1}

The first experiment was designed to study the effects of three intertrial intervals (ITI) on habituation of two responses and to determine which ITI(s) would be used to study spontaneous recovery in Experiment 2.

\section{Method}

Animals. One hundred and twenty male and female $A$. carolinensis, divided into six equal groups of comparable SVL, were arbitrarily assigned to one response and ITI condition.

Procedure. A given animal was tested on one response for 40 trials, each trial of $30 \mathrm{sec}$ duration, with a 5-, 30-, or $120-\mathrm{sec}$ ITl, and was then given five control trials with the same ITI and trial duration. Order of testing responses and ITIs was counterbalanced. A dewlap response was elicited from an anole by presenting a live house sparrow. Control trials involved applying firm pressure with thumb and forefinger to the base of an anole's tail while holding the anole $2.5 \mathrm{~cm}$ above the apparatus platform. Pilot work determined that such a procedure would effectively elicit the dewlap response and gaping. An OKR was elicited by rotating the striped cylinder counterclockwise; the direction of rotation was reversed during the control trials. These control procedures were introduced in Experiment 1 to determine if the observed decrement was due to effector fatigue. These procedures involved the presentation of another stimulus that elicited the response that was habituated. During control trials, there would likely be minimal or no increase in responding above the final test trial response levels if effectors were fatigued, since the same effectors employed during test trials are presumably stimulated during control trials. However, a significant increase in responding during control trials would indicate that the observed decrement was the result of habituation and not effector fatigue.

\section{Results}

Unless otherwise specified, analyses within and across responses were performed on means per fivetrial blocks.

Within-response systems. There were no differences between ITIs within any response on Trial 1 response levels [all $\operatorname{Fs}(2,57)<2.12$, ps $>.10$ ]. Control trial blocks (TB-9) were significantly greater than the final response levels (TB-8) for each response and ITI [all $F s(1,19)>10.05$, all ps $<.01$ ], indicating that the observed decrement was not due to effector fatigue (see Figure 3).

The ITI factor had a significant effect upon response levels for the OKR $[F(2,57)=6.29, \mathrm{p}<.01]$, but not for the dewlap response $[F(2,57)=.10]$. While Trial Blocks were significant within each response [all $F s(6,14)>22.5$, all ps $<.001$ ], there were no ITI by Trial Block interactions, thereby indicating a decreasing response pattern across trials for each ITI (Figure 3) and further substantiating the occurrence of habituation. Newman-Keuls tests 


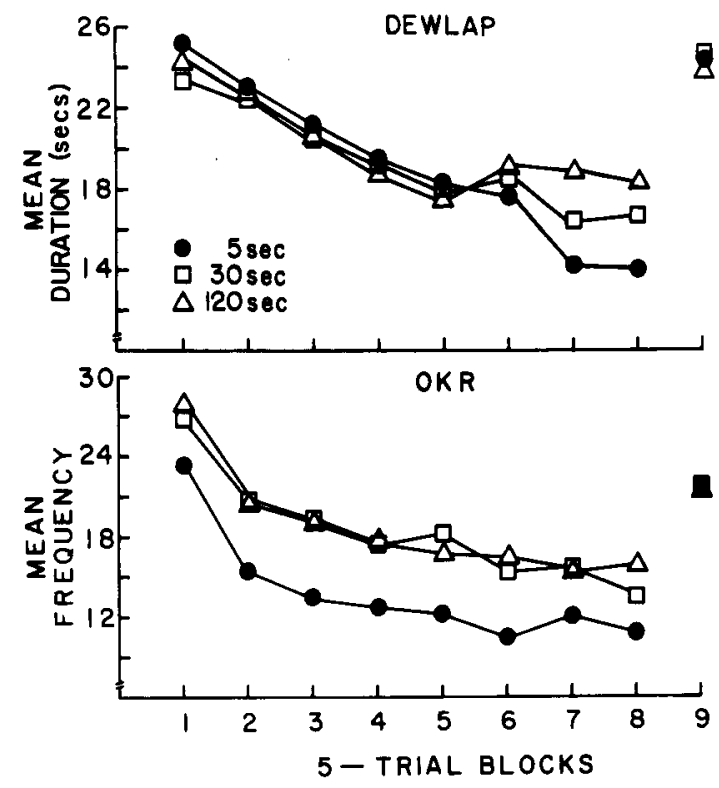

Figure 3. Mean duration of dewlap extension and frequency of optokinetic responses for the 5-, 30-, and 120 -sec intertrial intervals. Trial Block 9 consisted of control trials.

showed that the 5-sec ITI response level was significantly lower than the 30- and 120-sec ITI in the OKR (both ps $<.01$ ). The last 10 trials of the dewlap response did not differ between ITIs $[F(2,57)$ $=1.11, \mathrm{p}>.25]$. Although not shown here, only the dewlap response showed an initial increment in responding above Trial 1 response levels.

Inspection of individual data revealed that some smaller anoles within each ITI of the dewlap response did not habituate. Therefore, data for each response was further analyzed by dividing animals within each ITI into two groups according to SVL. One group was composed of 10 larger ( $>59-\mathrm{mm}$ SVL) sexually mature anoles (Fox \& Dessauer, 1958; Hamlett, 1952; Michael, 1972), the other group of 10 anoles was smaller $(50-59 \mathrm{~mm})$. Two-way repeated measures analyses of variance (Winter, 1971, p. 520) showed no differences between larger and smaller anoles under any ITI condition of the OKR [all Fs $(1,18)<2.75$ ]. However, while larger animals habituated under each ITI of the dewlap response, smaller anoles differed from larger anoles in showing no decrement under the 30 - or 120 -sec ITI $[$ Fs $(1,18)$ $=9.35$ and 16.37, respectively, ps $<.01$ ] (see Figure 4). An additional group of 10 small anoles (mean SVL $=54, \mathrm{SD}=2.71 \mathrm{~mm}$ ) were tested on the dewlap response with a $30-\mathrm{sec}$ ITI. This second group did not differ from the first 30 -sec ITI group of small anoles, demonstrating that the size effect is reliable and reproducible. The combined data for these two 30-sec ITI groups are presented in Figure 4. Larger anoles' dewlap response levels did not differ between ITIs $[F(2,27)=.76]$. Within each response, there were no differences between sizes [all Fs $(1,54)$
$<1.93$ ] or ITIs [all $\mathrm{Fs}(2,54)<2.32$ ] in the rate of habituation (number of trials to asymptote).

Unlike dewlap distension, gaping habituated under each ITI for both larger and smaller anoles. Because of the high variability of gaping, the data were treated as the percentage of larger and smaller animals that opened their mouths at least once in a five-trial block. Mouth-opened paralled the results of the dewlap response (see Figure 4), that is, no differences between larger and smaller animals in the 5 -sec ITI, while more smaller than larger anoles responded with a gape in the 30 - and $120-\mathrm{sec}$ ITI.

Across response systems. Response measures differed (i.e., duration and frequency); therefore, comparisons across responses under each ITI were standardized on the percentage initial response (defined as the response level of each trial divided by the first trial response level). Because of variability in percentage initial response, an arc sin transformation was employed and separate analyses were performed for larger and smaller animals. Three-way repeated measures analyses of variance (Winer, 1971, p. 559)

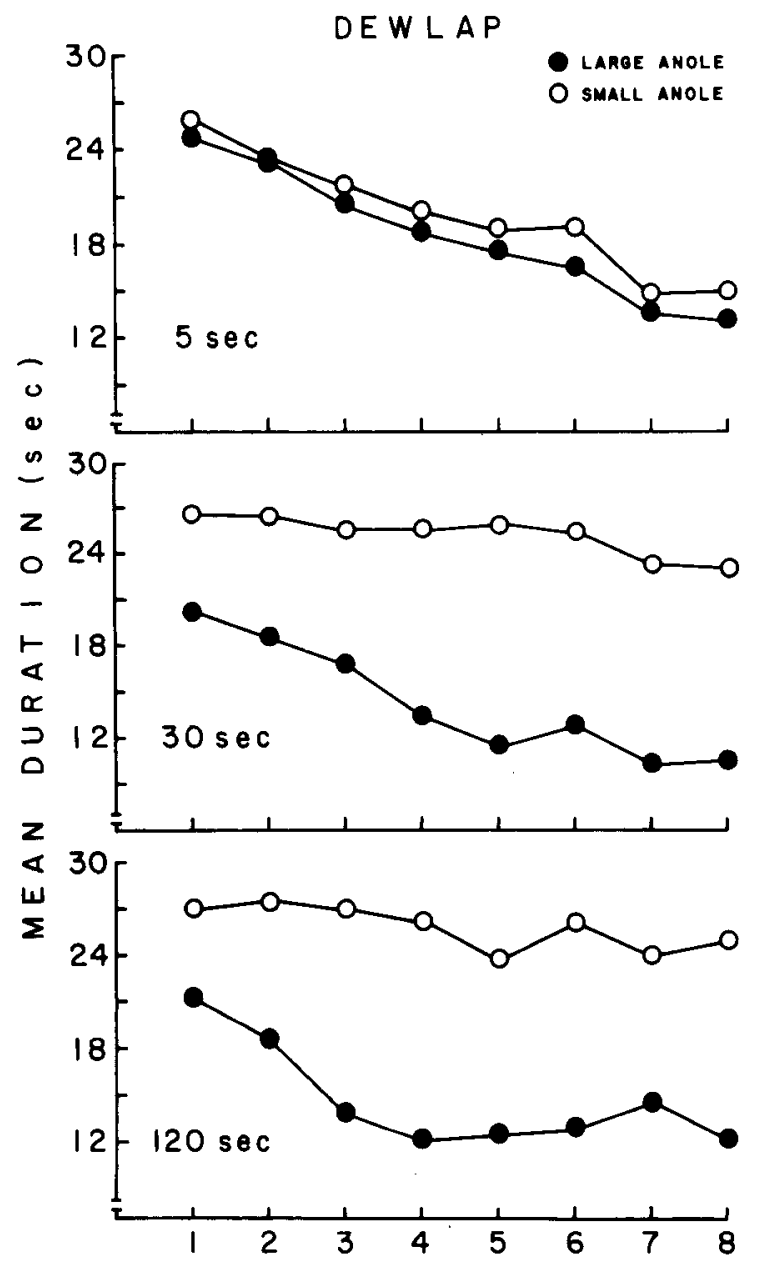

Figure 4. Mean duration of dewlap extension for large $(\geqslant 59-\mathrm{mm}$ SVL) and small (50-58-mm SVL) anoles under the 5-, 30-, and 120 -sec intertrial intervals. 
of the transformed data showed a significant response effect for larger and smaller anoles $[\mathrm{Fs}(1,54)=$ 5.22 and 24.80 , respectively, ps $<.05$ ]. No interactions were significant. Newman-Keuls tests revealed that for larger animals the percentage initial response of the dewlap response did not differ from that of the OKR within any ITI. For smaller anoles, the percentage initial response of the dewlap response and OKR differed within each ITI (all ps $<.01$ ). For larger and smaller anoles, the percentage initial response was similar within each ITI. Rates of habituation did not differ between responses under any ITI for larger or smaller anoles [all $\mathrm{Fs}(1,54)<1.66]$.

\section{Discussion}

The results of this experiment indicate that in A. carolinensis two different response systems exhibit habituation. For each response system, control test trials indicate that the observed decrement was not attributable to effector fatigue.

One of the parametric characteristics of habituation is that the use of shorter intertrial intervals typically results in faster habituation and/or lower levels of responding (Thompson \& Spencer, 1966). In the present study, intertrial interval had different effects across responses in that shorter ITIs results in lower levels of responding in only the OKR but not in the dewlap response. It is not unusual to find inconsistent effects of intertrial interval on the course of habituation. Shorter ITIs have resulted in both lower (Askew, 1970; Barrass, 1961; Thompson \& Spencer, 1966) and higher asymptotic levels of responding (Davis, 1970; File, 1973) than have longer ITIs, with no difference in the rate of habituation. It is not clear to what extent these inconsistencies are related to the different species and responses studied. The present results suggest that the differences between responses in the effects of intertrial interval on habituation may be related to the biological significance of the response system. For example, the dewlap response in $A$. carolinensis is important in several contexts, including intraspecific agonistic encounters, courtship, sexual receptivity, and mate selection, and possible as an interspecific isolated mechanism (Crews \& Williams, 1977; Williams \& Rand, 1977) and a defensive reaction to a potential predator (present results), while an optokinetic response is likely involved in detection and pursuit of prey. Intertrial intervals had different effects on these two responses. Whether habituation of other functionally different response systems can be differentiated on the basis of the frequency of stimulation remains to be determined.

Dewlap response. Only for habituation of the dewlap response was there a size effect. Larger anoles habituated under all ITI conditions, while smaller anoles failed to habituate with longer ITIs. The reasons for this difference remain unknown. Reproductive condition is known to differentially affect habituation in male and female white-crowned sparrows (Petronivich, Patterson, \& Peeke, 1975). And since dewlap distension in $A$. carolinensis is important in courtship and mate selection (Crews, 1975a), perhaps differences in habituation between larger and smaller anoles are related to the reproductive (and therefore hormonal) status of the animals. This possibility remains to be determined.

It is also possible that selection has favored the development of a nervous system which is slower to habituate during ontogeny than in adulthood, independently of hormonal influences. Slower or no habituation in younger animals has been reported for the prey-attack response of snakes (Burghardt, 1975), exploratory behavior of rats (Bronstein, 1972; Feigley, Parsons, Hamilton, \& Spear, 1972; Parsons, Fagan, \& Spear, 1973) and monkeys and chimpanzees (Green, 1965; Welker, 1956), and the acoustic startle response of mice (Groswald \& Luttges, 1974).

In $A$. carolinensis, distended dewlap and open mouth also occur during conspecific fighting and are usually accompanied by head nods or "bobbing" (rapid up-and-down head movements) (Crews, 1975b; B. Greenberg \& Noble, 1944; N. Greenberg, 1977). Bobbing movements were never observed in these experiments, suggesting that reaction to a bird is functionally distinct from intraspecific fighting which might habituate differently.

OKR. There were no size or sensitization (increased responding) effects on habituation of the OKR as there was in the dewlap response. Most of the OKR decrement occurred within the first 10-15 trials (5-7.5 min of rotation). This is consistent with previous findings for turtles in which OKR habituated within the first $10-15$ trials $(6 \mathrm{~min})$ of continuous rotation (Hayes et al., 1968). OKR in $A$. carolinensis and other anoline lizards appears to be correlated with microhabitat illumination (Jensen \& Swenson, 1974). It would be interesting to know whether other reptiles show a similar rapid decrement in OKR habituation, particularly among those with similar microhabitat illumination levels.

\section{EXPERIMENT 2}

Experiment 2 was designed to investigate the second parametric characteristic of habituation listed by Thompson and Spencer (1966): recovery and retention. Since recovery and retention may vary with the extent of habituation in the previous session (Hinde, 1970), the extent of habituation should be as similar as possible if comparisons across responses are to be meaningful. Because the dewlap and OKR habituation curves in the previous experiment were 
very similar for larger but not for smaller anoles, only larger anoles were employed in the present experiment.

\section{Method}

Animals. The subjects were 80 experimentally naive $A$. carolinensis ranging in size from $60-$ to $72-\mathrm{mm}$ SVL. The animals were divided into four groups of comparable SVL and were arbitrarily assigned to one response and recovery interval.

Procedure. The dewlap response and OKR were elicited as in Experiment 1. A given animal was tested twice on only one response with a $15-\mathrm{min}$ or 24 -h interval between sessions. Each session consisted of 40 trials, each trial of $30 \mathrm{sec}$ duration, with a $30-\mathrm{sec}$ ITI. The order of testing responses and recovery intervals was counterbalanced. When eliciting the dewlap response for any given anole, the same stimulus bird was employed for both sessions.

\section{Results}

Habituation occurred within each session of both responses, as shown in Figure 5. Within each response and prior to the recovery interval, the 15 -min and 24-h groups did not differ from each other on Trials 1 or 40 , TB-1 or TB-8 [all ts $(38)<1.11$, ps $>.10$, two-tailed], or on the total response curves $[F s(1,38)=.26$ and .05 for the dewlap response and $O K R$, respectively].

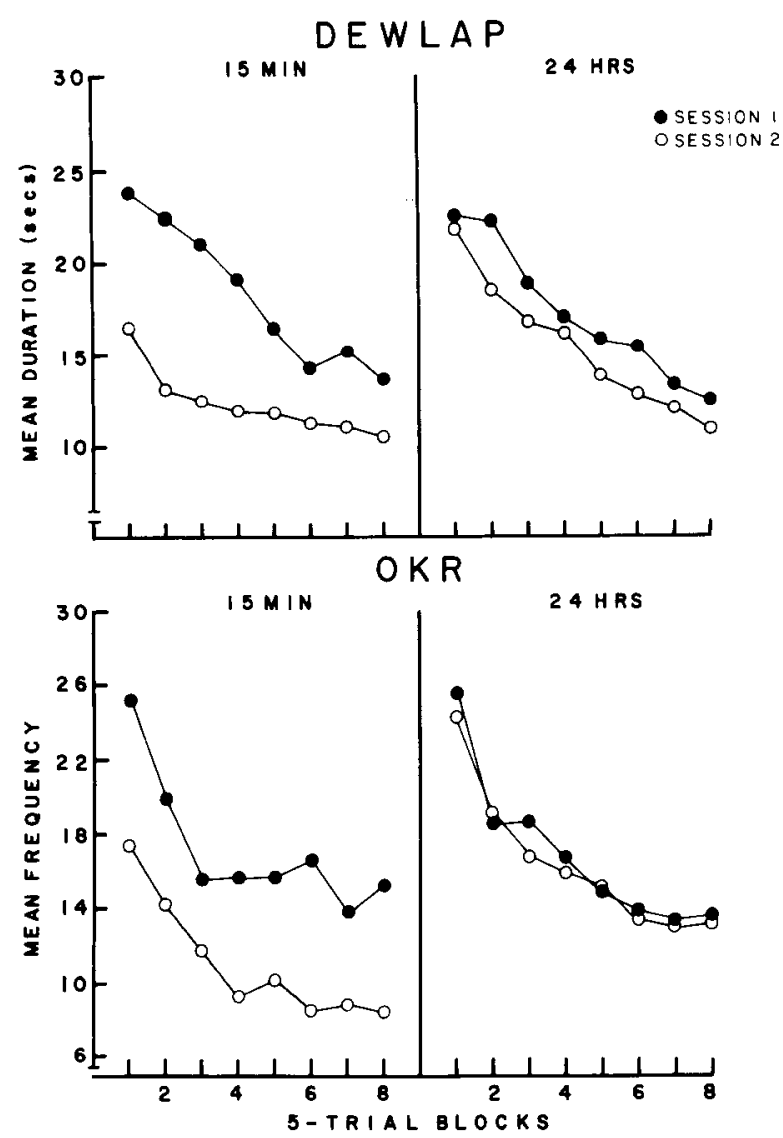

Figure 5. Mean duration of dewlap extension and frequency of optokinetic responses for Session 1 and Session 2 of the $15-$ inin and $24-\mathrm{h}$ recovery test.
Repeated measures analyses of variance (Winer, 1971 , p. 496) indicated significant retention of habituation (lower response levels) for the dewlap response and OKR after $15 \mathrm{~min}$ rest $[\mathrm{Fs}(1,19)=$ 28.11 and 76.48 , respectively, ps $<.001]$ but not after $24 \mathrm{~h}[\mathrm{Fs}(1,19)=3.49$ and .45 , respectively].

The amount of recovery (the difference in response level between the last trial of the first session and the first trial of the second session) for the OKR was greater after $24 \mathrm{~h}($ mean $=17.1)$ than after $15 \mathrm{~min}$ (mean $=8.9$ ) of rest $[\mathrm{t}(38)=2.78, \mathrm{p}<.01$, twotailed], while the dewlap response showed no differences between recovery intervals in the amount of recovery.

Data for mouth open were treated as in Experiment 1. Mouth-open results paralleled those for the dewlap in showing retention after $15 \mathrm{~min}$ but not after $24 \mathrm{~h}$.

\section{Discussion}

The dewlap response and OKR habituated as in Experiment 1 and substantially recovered from habituation after a 15-min interval and fully recovered in $24 \mathrm{~h}$. Retention was absent for both responses after $24 \mathrm{~h}$.

The recovery intervals did not differentiate between the dewlap response and OKR in the present experiment, although the recovery interval was an important parameter in differentiating response systems in other studies (cf. Hinde, 1970; Wyers et al., 1973). It is interesting to note, however, that the 15-min OKR group habituated even more in Session 2 after apparently reaching an asymptote in Session 1, while the 15-min dewlap group did not. The lack of retention after $24 \mathrm{~h}$ may be related to the number of trials employed (40); additional trials may result in the demonstration of long-term retention of an habituated response.

Dewlap response. The dewlap response would appear to be a defensive reaction employed to frighten or ward off a threatening stimulus, rather than removing the animal from the threatening situation. The dewlap response differs from other such defensive reactions in retention of habituation. For instance, the mobbing response of chaffinches shown towards predator models habituates and rapidly recovers to about $60 \%$ in $30 \mathrm{~min}$ with retention evident for days (Hinde, 1954, 1960). The deimatic (frightening) reaction of mantids to a predator and possible predators (live birds) waned within 30 3-min trials. Recovery was complete after 2 and 6 days of rest, with evidence of retention at both intervals (Balderrama \& Maldonado, 1971). In contrast, the dewlap response completely recovered within 15 min with no retention after $24 \mathrm{~h}$.

OKR. Substantial recovery of an OKR after a few minutes' rest and complete recovery after $24 \mathrm{~h}$ has 
also been found in turtles (Hayes et al., 1968). Hayes et al., employing a 19-stripe cylinder, found almost $50 \%$ recovery of the OKR with 2 min of rest and no retention of habituation after $24 \mathrm{~h}$. However, with a four-stripe drum, retention was present after $24 \mathrm{~h}$.

\section{GENERAL DISCUSSION}

Hodos and Campbell (1969), among others, have argued for the application of evolutionary theory to comparative psychology. Indeed, such evolutionary considerations have altered learning theory in several areas (e.g., Bolles, 1970; Rozin \& Kalat, 1971; Seligman, 1970; Shettleworth, 1972). Learning is thus viewed as an adaptive specialization with an evolutionary history. Animals may be limited as to what they can learn, these "constraints on learning" being a result of the operation of past selecton pressures (cf. Hinde \& Stevenson-Hinde, 1973; Seligman \& Hager, 1972).

Although other areas of learning have been significantly influenced by an evolutionary perspective, habituation has not. We suggest, along with others, that viewing habituation in the context of "constraints on learning" would also be likely to alter habituation theory. It is likely that habituation in various species and responses does not always fit the parametric characteristics of habituation listed by Thompson and Spencer (1966), but, rather, varies with the function of the response and the ecological significance of the stimulus.

For example, there are several single responsesystem studies suggesting that habituation is correlated with the ecological significance (Clark, 1960; Evans, 1969a, 1969b) or meaningfulness of the stimulus to an animal (Milligan \& Verner, 1971; Peeke \& Zeiner, 1970; see also Petrinovich, 1973). The differences noted in the course of habituation of two response systems of $A$. carolinensis provide additional support for such an argument.

A multiple response-system approach offers a promising research strategy for studying habituation within an evolutionary framework. It would seem reasonable to extend and to refine this method in order to evaluate the presumed similarities and differences in the physiological mechanisms and processes underlying habituation in different species and responses. Such an approach employed at both the behavioral and physiological levels and viewed from an evolutionary perspective would further understanding of habituation.

\section{REFERENCES}

Askew, H. R. Effects of stimulus intensity and intertrial interval on habituation of the head-shake response in the rat. Journal of Comparative and Physiological Psychology, 1970, 72. 492-497.
Askew, H. R., Leibrecht, B. C., \& Ratner, S. C. Effects of stimulus duration and repeated sessions of habituation of the head-shake response in the rat. Journal of Comparative and Physiological Psychology, 1969, 67, 497-503.

BalderRama, N., \& Maldonado, H. Habituation of the deimatic response in the mantid (Stagmatoptera biocellata). Journal of Comparative and Physiological Psychology, 1971, 75, 98-106.

BarRass, R. A quantitative study of the behavior of the male Mormoniella vitripennis (Walker) (Hymenoptera, Pteromalidae) towards two constant stimulus-situations. Behaviour, 1961, 18, 288-312.

Bolles, R. C. Species-specific defense reactions and avoidance learning. Psychological Review, 1970, 77, 32-48.

BronsteIn, P. M. Open-field behavior of the rat as a function of age: Cross-sectional and longitudinal investigations. Journal of Comparative and Physiological Psychology, 1972, 80, 335-341.

BURGHARDT. G. Effects of prey size and movement on the feeding behavior of the lizards Anolis carolinensis and Eumeces fasciatus. Copela, 1964, 576-578.

Burghardt, G. M. Stimulus control of the prey-attack response in naive garter snakes. Psychonomic Science, 1966, 4, 37.38.

Burghard, G. Chemical prey preference polymorphism in newborn garter snakes Thamnophis sirtolis. Behaviour, 1975, 52, 202-225.

Chiszar, D., Carter, T., Knight, L., Simonsen, L., \& TAYLOR, S. Investigatory behavior in the plain garter snake (Thamnophis radix) and several additional species. Animal Learning \& Behavior, 1976, 4, 273-278.

ClARK, R. B. Habituation of the polychaete Nereis to sudden stimuli. 2. Biological significance of habituation. Animal Behaviour, 1960, 8, 92-103.

Conant, R. A. Field guide to reptiles and amphibians (2nd ed.). Boston: Houghton Mifflin, 1975.

Crampton, G. H., \& SChwam, W. J. Turtle vestibular responses to angular acceleration with comparative data from cat and man. Journal of Comparative and Physiological Psychology, 1962, 55, 315-321.

CREws, D. Effects of different components of male courtship behaviour on environmentally induced ovarian recrudescence and mating preferences in the lizard, Anolis carolinensis. Animal Behaviour, 1975, 23, 349-356. (a)

CREWS, D. Inter and intraindividual variation in display patterns in the lizard, Anolis carolinensis. Herpetologia, 1975, 31, 37-47. (b)

CREws, D. Psychobiology of reptilian reproduction. Science, 1975, 189, 1059-1065. (c)

CrEWs, D., \& Williams, E. F. Hormones, reproductive behavior, and speciation. American Zoologist, 1977, 17, 271-286.

CzAplicki, J. Habituation of the chemically elicited preyattack response in the diamond-backed water snake, Natrix rhombifera rhombifera. Herpetologica, 1975, 31, 403-409.

DAvis, M. Effects of interstimulus interval length and variability on startle-response habituation in the rat. Journal of Comparative and Physiological Psychology, 1970, 72, 177-192.

Evans, S. M. Habituation of the withdrawal response in Nereid polychaetes. 1. The habituation process in Nereis diversicolor. Biological Bulletin. 1969, 137, 95-104. (a)

Evans, S. M. Habituation of the withdrawal response in Nereid polychaetes. 2. Rates of habituation in intact and decerebrate worms. Biological Bulletin, 1969, 137, 105-117. (b)

EWERT, J., \& INGLE, D. Excitatory effects following habituation of prey-catching activity in frogs and toads. Journal of Comparative and Physiological Psychology, 1971, 77, 369-374.

Feigley, D. A., Parsons, P. J., Hamilton, L. W., \& SPEAR, N. E. Development of habituation to novel environments in the rat. Journal of Comparative and Physiological Psychology, 1972, 79, 443-452.

FigLer, M. H. The relation between eliciting stimulus strength and habituation of the threat display in the male Siamese fighting fish, Betta splendens. Behaviour, 1972, 42, 63-96.

FILE, S. E. Inter-stimulus interval and the rate of behavioral habituation. Quarterly Journal of Experimental Psychology, $1973,25,360-367$. 
Fox, W., \& Dessauer, H. C. Response of the male reproductive system of lizards (Anolis carolinensis) to unnatural day-lengths in different seasons. Biological Bulletin, 1958, 115, 421-439.

Fuenzalida, C. E., Ulrich, G., \& Ichikawa, B. T. Response decrement to repeated shadow stimuli in the garter snake, Thamnophis radix. Bulletin of the Psychonomic Society, 1975 , 5. 221-222.

Goodman, D. A., \& Weinberger, N. M. Habituation in "lower" tetrapod vertebrates: Amphibia as vertebrate models. In H. V. S. Peeke \& M. J. Herz (Eds.), Habituation (Vol. 1): Behavioral studies. New York: Academic Press, 1973.

GREEN, P. C. Influence of early experience and age on expression of affect in monkeys. Journal of Genetic Psychology, 1965, 106, 157-171.

Greenberg, B.,\& Noble, G. K. Social behavior of the American chameleon (Anolis carolinensis Voight). Physiological Zoology, 1944, 17, 393-439.

GreenberG, N. A neuroethological study of display behavior in the lizard Anolis carolinensis (Reptilia, Lacertilia, Iguanidae). American Zoologist, 1977, 17, 191-201.

Groswald, D. E., \& Luttges, M. W. Developmental and genetic variables in mouse startle response habituation. Developmental Psychobiology, 1974, 8, 41-48.

HamletT, G. W. Notes on breeding and reproduction in the lizard Anolis carolinensis. Copeia, 1952, 183-185.

HaRRIS, J. D. Habituatory response decrement in the intact organism. Psychological Bulletin, 1943, 40, 385-423.

Hayes, W. N., Hertzler, D. R., \& Hogberg, D'. K. Visual responsiveness and habituation in the turtle. Journal of Comparative and Physiological Psychology, 1968, 65, 331-335.

HindE. R. A. Factors governing the changes in strength of a partially inborn response, as shown by the mobbing behaviour of the chaffinch (Fringilla coelebs). 2. The waning of the response. Proceedings of the Royal Society of London, Series B, 1954, 142, 331-359.

Hinde, R. A. Factors governing the changes in strength of a partially inborn response, as shown by the mobbing behaviour of the chaffinch (Fringilla coelebs). 3. The interaction of shortterm and long-term incremental and decremental effects. Proceedings of the Royal Society of London, Series B, 1960, 153, 398-420.

Hinde, R. A. Behavioural habituation. In G. Horn \& R. A. Hinde (Eds.), Short-term changes in neural activity and behaviour. New York: Cambridge University Press, 1970.

Hinde, R. A., \& Stevenson-Hinde, J. (Eds.), Constraints on learning. New York: Academic Press, 1973.

Hodos, W., \& Campbell, C. B. G. Scala naturae: Why there is no theory in comparative psychology. Psychological Review, 1969, 76, 337-350.

HuMPhREY, G. The nature of learning in its relation to the living system. New York: Harcourt, Brace, 1933.

JensSen, T. A., \& Swenson, B. An ecological correlate of critical flicker-fusion frequencies for some Anolis lizards. Vision Research, 1974, 14, 965-970.

LEATON, R. N. Long-term retention of the habituation of lick suppression in rats. Journal of Comparative and Physiological Psychology, 1974, 87, 1157-1164.

LICHT, P. Regulation of the annual testis cycle by photoperiod and temperature in the lizard Anolis carolinensis. Ecology, $1971,52,240-252$.
LORENZ, K. Evolution and modification of behavior. Chicago: University of Chicago Press, 1965.

Michael, E. D. Growth rates in Anolis carolinensis. Copeia, 1972, 575-577.

Milligan, M. M., \& Verner, J. Inter-populated song dialect discrimination in the white-crowned sparrow. Condor, 1971, 73, 208-213.

Noble, G. K., \& Bradley, H. T. The mating behavior of lizards: Its bearing on the theory of sexual selection. Annals of the New York Academy of Science, 1933, 35, 25-100.

Parsons, P. J., Fagan, T., \& Spear, N. E. Short-term retention of habituation in the rat: A developmental study from infancy to old age. Journal of Comparative and Physiological Psychology, 1973, 84, 545-553.

Peeke, H. V. S., \& Zeiner, A. R. Habituation to environmental and specific auditory stimuli in the rat. Communications in Behavioral Biology, 1970, 5, 23-29.

Petrinovich, L. A species-meaningful analysis of habituation. In H. V. S. Peeke \& M. J. Herz (Eds.), Habituation (Vol. 1): Behavioral studies. New York: Academic Press, 1973.

Petrinovich, L., Patterson, T., \& Peeke, H. V. S. Reproductive condition and the response of white-crowned sparrows (Zonotrichia leucophrys nuttalli) to song. Science, 1976, 191, 206-207.

Polyak, S. The vertebrate visual system. Chicago: University of Chicago Press, 1957.

Powell, R. W. Avoidance and escape conditioning in lizards. Psychological Reports, 1967, 20, 583-586.

Rozin, P., \& Kalat, J. W. Specific hungers and poison avoidance as adaptive specializations of learning. Psychological Review, 1971, 78, 459-486.

Seligman, M. E. P. On the generality of the laws of learning. Psychological Review, 1970, 77, 406-418.

Seligman, M. E. P., \& Hager, J. L. (Eds.). Biological boundaries of learning. New York: Appleton-Century-Crofts, 1972.

Shettleworth, S. J. Constraints on learning. Advances in the Study of Behavior, 1972, 4, 1-68.

TAUber, E., \& ATKIN, A. Optomotor responses to monocular stimulation: Relation to visual system organization. Science, $1968,160,1365-1367$.

Thompson, R. F., \& Spencer, W. A. Habituation: A model phenomenon for the study of neuronal substrates of behavior. Psychological Review, 1966, 73, 16-43.

Thorpe, W. H. Learning and instinct in animals. Cambridge, Mass: Harvard University Press, 1963.

WELKER, W. I. Effects of age and experience on play and exploration of young chimpanzees. Journal of Comparative and Physiological Psychology, 1956, 49, 223-226.

Williams, E. E., \& Rand, A. S. Species recognition, dewlap function and faunal size. American Zoologist, 1977, 17, 261-270.

WINER, B. J. Statistical principles in experimental design (2nd ed.). New York: McGraw-Hill, 1971.

Wyers, E. J., Peeke, H. V. S., \& Herz, M. J. Behavioral habituation in invertebrates. In H. V. S. Peeke \& M. J. Herz (Eds.), Habituation (Vol. 1): Behavioral studies. New York: Academic Press, 1973.

(Received for publication January 3, 1978; revision accepted May 29, 1978.) 